\title{
Isolation, Culturing, Characterization and Aging of Adipose Tissue-derived Mesenchymal Stem Cells: A Brief Overview
}

\author{
Ezzatollah Fathi ${ }^{1}$; Raheleh Farahzadi ${ }^{2 *}$

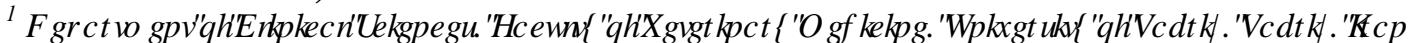 \\ ${ }^{2}$ Young Researchers And Elite Club, Tabriz Branch, Islamic Azad University, Tabriz, Iran.
}

\begin{abstract}
The aim of this review was to describe the current state-of-the-art regarding isolation, characterization and aging of adipose tissue-derived mesenchymal stem cells (ADSCs). Mesenchymal stem cells (MSCs) have recently received widespread attention because of their potential use in tissue-engineering applications. Various studies have indicated that MSCs with a fibroblast-like morphology migrate to the sites of injury and help to regenerate damaged tissue. Over the past few years, it has been recognized that fat is not only an energy supply, but also a rich source of multipotent stem cells that can be easily harvested, isolated and selected as compared with other tissues. ADSCs are particularly interesting because of their rapid proliferation and multidirectional differentiation potential.
\end{abstract}

Keywords: Adipose tissue-derived mesenchymal stem cells, adipose tissue, isolation, aging, differentiation potential.

*Author for correspondence: r.farahzadi@iaut.ac.ir 


\section{CHARACTERIZATION AND APPLICATION OF ADSCs}

The pioneering work of Cohnheim in 1867 on non-hematopoietic stem cells in the bone marrow followed by Friedenstein and coworkers in the 1960 s on the isolation, culture, and osteogenic differentiation of bone-marrow-derived cells from guinea pigs opened a new field of stem cell research (Friedenstein et al. 1974; Banas et al. 2007; Ko et al. 2007; Baer and Geiger 2012; Fathi and Farahzadi 2015). They discovered that the bone marrow contained fibroblastoid cells with clonogenic potential in vitro, which were capable of forming colonies (CFU-F). Almost 20 years later, subsequent investigations by Caplan introduced the stromal and mesenchymal stem cells (MSCs) terms to the scientific community and mentioned that human MSCs were also able to differentiate into adipocyte cell lineage (Caplan 1991; Baghaban Eslaminejad et al. 2009; Baer and Geiger 2012). Stem cells are characterized by the ability to renew themselves and to differentiate into many different cell types in the body. There are two kinds of stem cells isolated from the animals and humans: embryonic stem cells (ESCs), which are derived from the inner cell mass of blastocyst that are formed several days after an egg is fertilized, and non-embryonic stem cells, also known as adult stem cells that are attained from different tissues. Although ESCs exhibit an almost unlimited differentiation potential, they are not available in the medical and research practice because of the significant ethical, legal and political concerns (Ko et al. 2007; Abd El Samad 2011; Ahmad and Shakoori 2013).

There are different sources of stem cells for different applications. However, sources are preferred that allow minimally invasive procedures and recovery of abundant quantities of cells (Gimble 2003). Variable number of stem cells is present in different tissues such as liver, heart, kidney, skin, bone marrow, adipose tissue, placenta, dental, amniotic fluid, amnion and umbilical cord blood as well as in various fetal tissues (Wei et al. 2000; Banas et al. 2007). Earlier it was considered that stem cells can only differentiate into mature cells of the same organ but recent evidences have shown that they can also differentiate into other cell types and even into the cells of ectoderm, mesoderm and endoderm (Beltrami et al. 2001; De Ugarte et al. 2003; Jin et al. 2007; Vieira et al. 2010; Ren et al. 2012). It has been demonstrated that MSCs include a heterogeneous population of cells with multilineage differentiation potential, ability to modulate oxidative stress, and produce a variety of factors that are capable of manipulating a broad range of biological functions (Caplan 2007). The most important are angiogenesis, secretion of neuroregulatory peptides, growth factors and cytokines that can have immunomodulatory, angiogenic, anti-inflammatory and anti-apoptotic effects (Caplan 2007; Fathi et al. 2013). In general, human mesenchymal stem cell (hMSCs) from different sources share many biological features, although there are some differences in morphology, immunophenotype, proliferative capacity, differentiation potential, gene expression profile, proteome, immunomodulatory activity and utility for specific medical applications (Strioga et al. 2012). The potential use of these cells as a therapy in a wide range of clinical trials has been performed (e.g., for cardiac events, stroke, multiple sclerosis, blood diseases, auto-immune disorders, ischemia, cartilage and bone pathologies and genetic diseases) (Valenti et al. 2015). Fetal MSCs have been observed in maternal peripheral blood, suggesting that fetal surface antigens could be considered biomarkers for a noninvasive prenatal diagnosis, and the analysis of these cells in the amniotic fluid represents a useful tool for the identification of neural tube defects (Pennington et al. 2013). These stem cells are considered to have more plasticity and under certain culture conditions, they can easily be differentiated in vitro into multiple types of lineages such as: chondrogenic, osteogenic, adipogenic, myogenic, neurogenic, and hepatogenic (Noer et al. 2006; Banas et al. 2007; Abd El Samad 2011). Human MSCs can differentiate into other mesodermal tissues such as skeletal muscle (Dezawa et al. 2005), myocardium (Shim et al. 2004), smooth muscle (Jeon et al. 2006), and endothelium (Oswald et al. 2004). Herrera et al. (2004) found that mouse mesenchymal stem cells (mMSCs) engrafted in the damaged kidney differentiated into tubular epithelial cells and promoted the recovery of morphological and functional alterations. The ability of MSCs to differentiate in vitro could be of great clinical significance (Baghaban Eslaminejad et al. 2009). Bone marrow mesenchymal stromal cells (BM-MSCs) have multipotent properties suitable for tissue engineering and regenerative 
medical applications. However, BM-MSCs are not abundant, cell harvesting requires an invasive technique, and the cells are easily contaminated (Ren et al. 2012). Adult stem cells (ASCs) can be derived from different sites other than the bone marrow. Adipose tissue has become a rich source of MSCs providing an abundant and accessible source of ASCs with minimal patient discomfort. It lacks donor limitation, and obtaining these stem cells has a low risk of side effects. These cells are fibroblast-like cells capable of multipotential differentiation, which have been found in different species and have been termed ADSCs (Bianco et al. 2001; Vieira et al. 2010). The terms "adiposederived adult stem (ADAS) cells", "adiposederived stromal cells (ADSC)", "adipose stromal cells (ASC)", "adipose mesenchymal stem cells (AdMSC)", "preadipocytes", "processed lipoaspirate (PLA) cells", and "adipose-derived stromal/stem cells " for the cells isolated almost by a similar isolation procedure (plastic adherence) have been used in the literature. To eliminate this variation, the International Fat Applied Technology Society (IFATS) reached a consensus to adopt the term "adipose-derived stromal/stem cells" to identify the plastic adherent, cultured and serially passaged, multipotent cell population from adipose tissue (Mitchell et al. 2006; Gimble et al. 2007).

ADSC application is much less expensive than BM-MSC use, and the stem cell numbers that can be extracted from the isolated adipose tissue is higher than for BM-MSCs (Dicker et al. 2005). One gram of human adipose tissue yields approximately $5 \times 10^{9}$ stem cells, 500 times the number of MSCs harvested from one gram of bone marrow (Hall et al. 2010). ADSCs were able to keep strong proliferative ability, maintain their phenotypes, and have stronger multi differentiation potential after 25 passages (Zhu et al. 2008). The one study by Zhu et al. (2008) showing the relationship between different subculture time and growth ability. This showed that human ADSCs of passage 25 after being subcultured every 14 days also have renewable ability even stronger than passage 25 cells that were subcultured every five days. The results of this study indicated that in order to obtain more and higher quality cells, ADSCs could be subcultured every 14 days instead of the normal five days. ADSCs possess similar surface markers and differentiation potential as BM-MSCs, and can differentiate into cell types of the three germ layers under appropriate conditions (Ren et al. 2012). The differentiation potential of ASCs into cells of ecto- and endodermal origin has also been shown (Baer et al. 2012). Therefore, the term multipotent stem cells would be correct for ADSCs, as a differentiation into cells from all three germ layers has been shown (Baer et al. 2012).

In general, MSCs are isolated by their capacity to adhere to culture-dish plastic. The cells can be expanded in the culture while maintaining their multipotency during standard cell culture and are immunologically characterized by a specific panel of markers. However, the characterization of MSCs remains difficult due to the lack of definitive and unique cellular markers. Therefore, the International Society for Cellular Therapy proposed three minimal criteria for the definition of cultured MSCs: (a) plastic adherence, (b) expression of CD73, CD90, and CD105 and lack of CD34, CD45, CD11b or CD14, CD19 or CD79 $\alpha$ and HLA-DR expression, and (c) their trilineage differentiation potential into adipocytes, chondrocytes, and osteoblasts (Oedayrajsingh Varma et al. 2007). The immunophenotype of MSCs changes over the course of culturing; some of these changes may represent alterations in the biological features of MSCs; for example, in murine BM-MSCs the loss of expression of CD90, CD15 and CD309 associated with the spontaneous neoplastic transformation after numerous passages (Ren et al. 2012). Human MSCs have largely been shown to be free of such transformative events (Ren et al. 2012).

MSCs are attractive candidates for clinical applications such as tissue engineering, organ transplantation and repair damaged tissues in cardiovascular diseases and inflammatory disease, especially because these cells hold no ethical concerns and can be isolated in appropriate amounts from several sources and expanded in culture (Hall et al. 2010). Some studies demonstrated that mouse ADSCs could release multiple angiogenic growth factors and cytokines/chemokines. These suggest that they may have potential as a useful cell source for therapeutic angiogenesis (Efimenko et al. 2011). Fernández-García et al. (2015) indicated that ADSCs improve the homing of donor hematopoietic stem and progenitor cells into recipient bone marrow, facilitating the stable reconstitution of transplanted recipients with infused hematopoietic grafts. These results 
opening new perspectives in the application of AdSCs in hematopoietic stem cell gene therapy. In another study, Kim et al. (2015) showed that Platelet-derived growth factor-D can be considered a novel ADSCs stimulator, and used as a preconditioning agent before ADSCs transplantation.

Furthermore, their therapeutic potential in veterinary medicine has been available since 2003 and has been used in more than 2500 horses and more than 500 dogs (Hall et al. 2010).

The isolation method and the cytological characterization of stromal precursor cells from adipose tissue were shown at the beginning of the 1970s (Poznanski et al. 1973). ADSCs have been obtained from bovine, dog, goat, horse, rabbit, rat, mouse, pig and human (Noer et al. 2006; Vidal et al. 2007; Jin et al. 2007; Torres et al. 2007; Yamamoto et al. 2007; Williams et al. 2008; Vieira et al. 2010; Hall et al. 2010; Nakanishi et al. 2011; Abd El Samad 2011; Ren et al. 2012; Strioga et al. 2012; Ahmad and Shakori 2013). It has been published for ADSCs that liposuction side, liposuction procedure, variations in the isolation techniques, growth media, culture conditions, age or body mass index play an important role in the cell yield, growth, and frequency of stem cells causing a remarkable difference in their proliferation and differentiation capacity (Tsai et al. 2006; Jurgens et al. 2008; Baer et al. 2012). For example, Zhu et al. (2009) showed that the osteogenic potential of human female ADSCs decreased with the age, but the adipogenic potential remained unchanged.

\section{ADSCS HARVESTING, ISOLATION AND CULTURING}

Adipose tissue is obtained from different organs such as abdominal subcutaneous, inguinal, kidney, or epididymis under sterile conditions (Banas et al. 2007; Zaminy et al. 2008; Park et al. 2010; Ren et al. 2012; Ahmad and Shakori 2013; Huangm et al. 2013). Adipose tissues are transported to the laboratory in phosphate-buffered saline (PBS) solution or Dulbecco's Modified Eagle's Medium (DMEM) containing antibiotics within $2 \mathrm{~h}$ postsurgery for further procedures (Banas et al. 2007; Ahmad and Shakori 2013). Adipose tissue is minced with fine scissors and surgical scalpels into less than $3 \mathrm{~mm}^{3}$ pieces. The adipose tissue is washed extensively with sterile equal volumes of
PBS or Hank's balanced salt solution (HBSS) containing antibiotics to remove the contaminating debris and red blood cells (Noer et al. 2006; Jin et al. 2007; Vieira et al. 2010). To isolate ADSCs, the sample is spun at $2000 \mathrm{rpm}$ for $5 \mathrm{~min}$ to collect the fat tissue pieces. The fat pieces are washed extensively with sterile equal volumes of PBS three times and treated with $0.01 \%$ (Park et al. 2010; Ahmad and Shakori 2013), or 0.075\% (De Ugarte et al. 2003; Ko et al. 2007; Banas et al. 2007; Vieira et al. 2010), or 0.1\% (Jin et al. 2007), or $0.2 \%$ (Ren et al. 2012) type I collagenase prepared in PBS (De Ugarte et al. 2003; Ko et al. 2007; Banas et al. 2007; Jin et al. 2007; Vieira et al. 2010; Ren et al. 2012; Cardoso et al. 2012) or DMEM medium for 30 to $120 \mathrm{~min}$ at $37^{\circ} \mathrm{C}$ with gentle agitation after every $10 \mathrm{~min}$ (Ko et al. 2007; Ahmad and Shakori 2013) (Fig.1). Enzyme activity is neutralized with DMEM high or low glucose containing 10\% fetal bovine serum (FBS) and centrifuged at $1200 \mathrm{rpm}$ for $10 \mathrm{~min}$ to obtain a pellet. The pellet is re-suspended in complete medium (DMEM containing 10-15\% FBS, 100 $\mathrm{U} / \mathrm{mL}$ penicillin, and $100 \mu \mathrm{g} / \mathrm{mLstreptomycin}$ ) and filtered through a $100 \mu \mathrm{m}$ nylon mesh to remove the cellular debris (Ko et al. 2007; Jin et al. 2007; Ahmad and Shakori 2013). The number of cells is counted by hemocytometer and the cells are allowed to adhere to a plastic culture plate at $10^{4}$ cells $/ \mathrm{cm}^{2}$ and incubated overnight at $37^{\circ} \mathrm{C}$ under $5 \% \mathrm{CO}_{2}$. These steps remove the contaminating blood cells because they do not adhere to the plastic (Ko et al. 2007). Following incubation, cells are washed with PBS $24-48 \mathrm{~h}$ after plating to remove the unattached cells and fed with fresh media (Vieira et al. 2010). Culture medium is changed after 3-5 days to remove the non-adherent cells and twice weekly thereafter. The primary cells are cultured for 4-5 days until they reach the confluence and are defined as passage "0" (De Ugarte et al. 2003; Ko et al. 2007; Ren et al. 2012; Ahmad and Shakori 2013) (Fig. 2). The cells typically reach confluence in four to six days (Ko et al. 2007). The cells are then harvested by digestion with $0.05 \%$, or $0.25 \%$ trypsin-EDTA, centrifuged at $1200 \mathrm{rpm}$ for $5 \mathrm{~min}$, re-suspended in complete medium and plated at a density of approximately $10^{4} \mathrm{cells} / \mathrm{cm}^{2}$. Cells are passaged with trypsin-EDTA upon reaching 80-90\% confluency and expanded until passage 4, whereupon they are cultured until confluent and differentiation potential analyzed. The remaining cells are cryopreserved in cryopreservation media 
(10\% dimethylsulfoxide, 10\% DMEM, 80\% FBS), frozen at $-80^{\circ} \mathrm{C}$ for $24 \mathrm{~h}$, and stored in liquid

nitrogen the next day (Vieira et al. 2010; Ren et al. 2012; Ahmad and Shakori 2013).

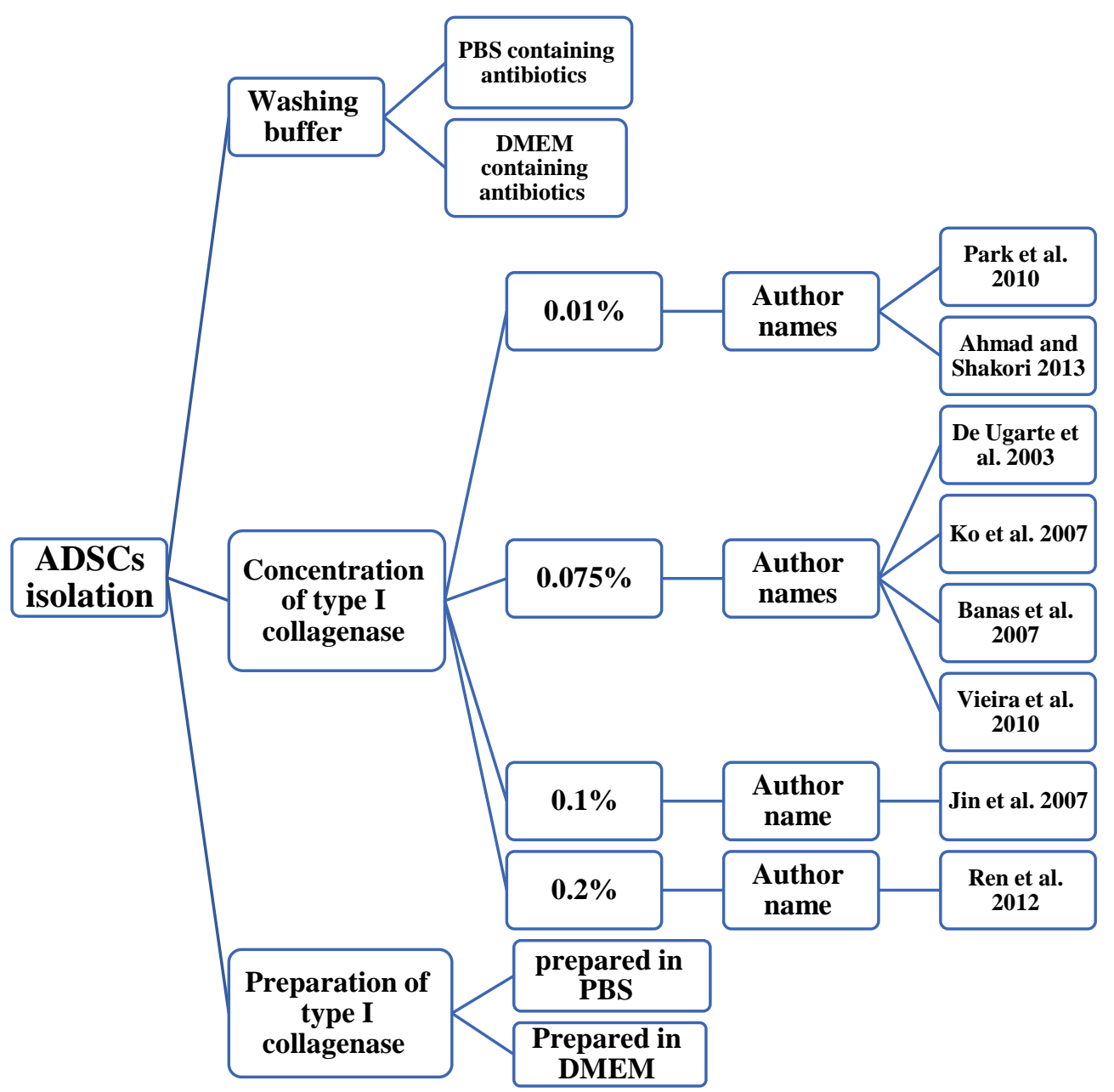

Figure 1- Different protocols for adipose tissue-derived mesenchymal stem cell isolation

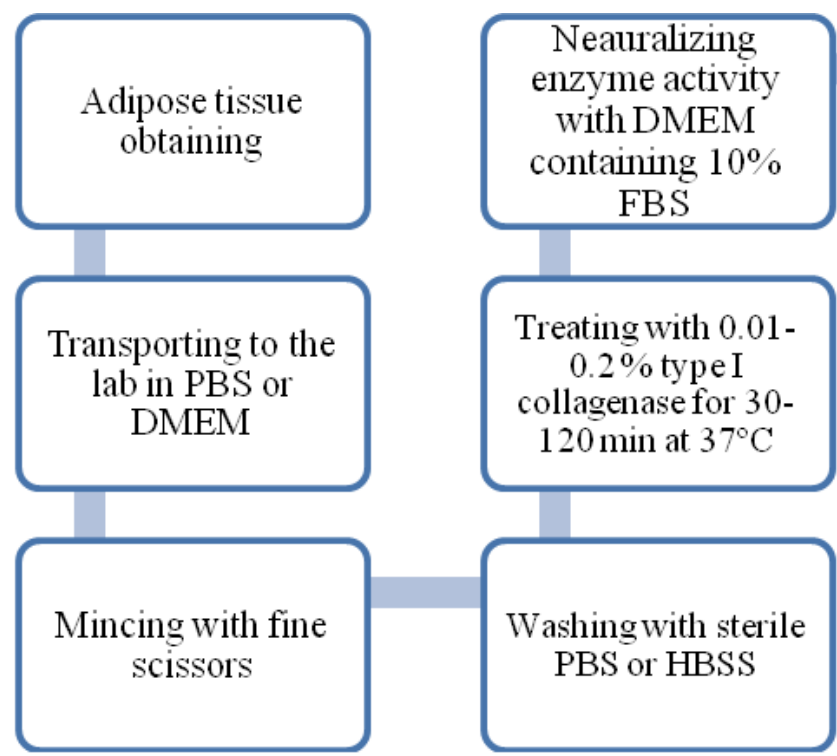

Centrifuging at 1200 $\mathrm{rpm}$ for $10 \mathrm{~min}$

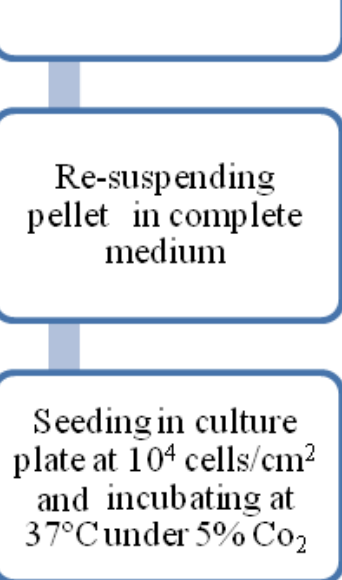

Figure 2- Diagram for adipose tissue-derived mesenchymal stem cells isolation 


\section{ADSC AGING}

Aging is a complex process that affects most of the biological functions of an organism, generally culminating in disease and death due to the accumulation of different types of stress such as oxidative reactions, telomere shortening and the decline of the DNA repair. Similar to normal somatic cells, adult stem cells are exposed to stressors during the life span, leading to an agedependent decline in their number and function. Many studies have constantly considered a senescent tendency of MSCs upon expansion (Tsai et al. 2006). Furthermore, the difference in stem cell properties and the senescence encountered during the expansion hinder the clinical applications of MSCs. Thus, evaluating stem cell aging status is essential for the successful use of stem cells in clinical practices (Tsai et al. 2006). "In vitro" studies have shown that human ADSCs age after about 30 population doublings (MezaZepeda et al. 2008) consequently losing adipogenic differentiation capacity (Noer et al. 2007). It should be noted that differences in the doubling times of ADSCs originating from different anatomical regions of the body have been reported (Hass et al. 2011). For example, the mean doubling time of the umbilical cord-derived human MSCs at passage 1 (P1) was determined to be approximately $24 \mathrm{~h}$ and remained almost constant up to P10. In contrast, the mean doubling time of human BM- MSC was $40 \mathrm{~h}$ and increased considerably after P6 (Lu et al. 2006). Van Harmelen et al. (2004) found that ADSCs from subcutaneous adipose tissue region proliferated faster (doubling time, $4+/-1$ days) than those from the omental (the layer of tissue around the stomach and intestines) region (doubling time, 5 +/- 1 days). Kern et al. (2006) investigated the senescence ratio of ADSCs in comparison to BMMSC. Human ADSCs could be cultivated up to P8 without any sign of senescence whereas in human BM-MSCs this process started from P7 (Kern et al. 2006; Hass et al. 2011).

Some studies found that in rat and human aged ADSCs, the mRNA expression level and protein content of p53 increased (Efimenko et al. 2011). One of the factors involved in both proliferation and senescence is c-myc a tumor promoter gene. In aged human ADSCs, c-myc is down-regulated similar to other senescent cell types (Mallette et al. 2007). All mentioned features were accompanied by telomere shortening. Reduction in proliferation potential was shown in aged human ADSCs as compared to young ADSCs (Meza-Zepeda et al. 2008). Another study demonstrated that the culture of human MSC under hypoxic conditions was accompanied by increased Oct4 expression and telomerase activity, which were involved in stemness maintenance (Hass et al. 2011). Tsai et al. (2006) demonstrated that hypoxic culture not only prevented the replicative senescence noted in expanded human MSCs, but also increased lifespan, proliferation capacity, differentiation efficiency, and maintained stem cell properties. The underlying mechanism was described to depend on down-regulation of E2A-p21 by the HIF-TWIST pathway (Tsai et al. 2006). Expression of p21 also induced by p53 and acted as a suppressor of cell-cycle progression. After p21 activation, cells undergo senescence and induce apoptosis. Although p21 expression and senescence have been reported to impair the efficiency of somatic cell reprogramming, the roles of p21 in stem cell properties and pluripotency regulation have not been elucidated (Tsai et al. 2006). The same report also demonstrated that TWIST, suppressed the E2A transcription to inhibit p21 expression, through direct binding to E-boxes of E2A promoter. In addition, knockdown of p21 induced the cell growth and increased stem cell properties under normoxia (Tsai et al. 2006). Furthermore, it was found that up-regulation of E2A in expanded MSCs, induced p21 to cause cell-cycle arrest and replicative senescence (Tsai et al. 2006).

Therefore, in vitro primary culture in a normoxic atmosphere $\left(21 \% \mathrm{O}_{2}\right)$ can be considered as an exposure to enhanced oxidative stress and promotes the generation of metabolic radicals, or reactive oxygen species (ROS) (Hass et al. 2011). Indeed, human MSCs cultured under normoxic conditions exhibit premature senescence and a reduction in population doublings in comparison to the cells cultured under hypoxia and may also show restricted cell division due to telomere shortening and replicative senescence (Wagner et al. 2010). Methods enhancing the lifespan, or stem cell properties of MSCs include retroviral transduction of the human telomerase gene, HPV16 E6E7, and the combined use of growth factors in a serum-free culture (Tsai et al. 2006). Therefore, the use of proper methods for reducing stem cell senescence is necessary. 


\section{ADSC DIFFERENTIATION POTENTIAL}

By definition, stem cells are able to self-renew, exist in an undifferentiated or unspecialized state, and are capable of differentiation, or specialization into lineage-specific cell types (Ko et al. 2007). The in vitro differentiation of ADSCs into multiple cell types of mesodermal origin has been shown in a variety of studies. Some studies have described the plasticity of ADSCs towards chondrocytes, osteoblasts, adipocytes, and myocytes (Ko et al. 2007; Vieira et al. 2010; Ren et al. 2012). In vitro differentiation into hepatocytes, pancreatic islet cells, neural cells, endothelial cells and epithelial cells and renal epithelial cells has been reported (Shim et al. 2004; Ko et al. 2007; Baghaban Eslaminejad et al. 2009; Vieira et al. 2010; Ren et al. 2012). Generally, the in vitro induction of ADSCs differentiation is mainly achieved by the culture in selective media with lineage specific induction factors. For example, to differentiate ADSCs into osteoblasts and adipocytes, osteogenic and adipogenic culture medium consists of DMEM supplemented with dexamethasone, $\beta$-glycerolphosphate and DMEM supplemented with dexamethasone, isobutylmethylxanthine and indomethacin were used, respectively.

Compare to adult stem cells, embryonic stem cells possess better multiplication and differentiation abilities. However, due to various ethical restrictions, the extent of clinical application is currently limited (Ko et al. 2007; Ren et al. 2012). As previously mentioned, because BM-MSCs are not abundant, cell harvesting requires a highly invasive procedure, and the cells are easily contaminated during the culturing. BM-MSCs are not ideal seeding cells for old patients because these cells remarkably lose their differentiation ability with the donor age increasing (Jing et al. 2008). Adipose tissue is abundant, readily expendable and easy to obtain from the body (Ren et al. 2012). According to Jing et al. (2008), ADSCs showed excellent pluripotency potential and many advantages over the BMSCs, and their osteogenic potential could be maintained with aging. Thus, ADSCs are particularly interesting candidate for cell therapy and tissue engineering (Ko et al. 2007; Jing et al. 2008).

In conclusion, as found by Al-Nbaheen et al. (2013), MSC populations obtained from different tissues exhibited significant differences in their proliferation and differentiation, which should be taken into consideration when planning their use in clinical protocols (Al-Nbaheen et al. 2013).

\section{REFERENCES}

Abd El Samad AA. 2011. Stem cells: new different sources and applications in regenerative medicine. Egypt J Histol. 2011; 24: 1-4.

Ahmad A, Shakoori AR. Cytotoxic and Genotoxic effects of Arsenic and Lead on Human Adipose Derived Mesenchymal Stem Cells (AMSCs). J Stem Cells Reproduc Med. 2013; 9: 1-8.

Al-Nbaheen M, Vishnubalaji R, Ali D, Bouslimi A, AlJassir F, Megges M, et al. Human stromal (mesenchymal) stem cells from bone marrow, adipose tissue and skin exhibit differences in molecular phenotype and differentiation potential. Stem Cell Rev and Rep. 2013; 9: 32-43.

Baer PC, Geiger H. Adipose-derived mesenchymal stromal/stem cells: tissue localization, characterization, and heterogeneity. Stem Cells Int. doi:10.1155/2012/812693, 2012; 1-11.

Baghaban Eslaminejad MR, Taghiyar L, Dehghan MM, Falahi F, Kazemi Mehrjerdi H. Equine marrowderived mesenchymal stem cells: isolation, differentiation and culture optimization. Iran $\mathrm{J} \mathrm{Vet}$ Res. 2009; 10: 1-11.

Banas A, Teratani T, Yamamoto Y, Tokuhara M, Takeshita F, Quinn G, et al. Adipose tissue-derived mesenchymal stem cells as a source of human hepatocytes. Hepatol. 2007; 46: 219-228.

Beltrami AP, Urbanek K, Kajstura J, Yan SM, Finato $\mathrm{N}$, Bussani R, et al. Evidence that human cardiac myocytes divide after myocardial infarction. $N$ Engl $J$ Med. 2001; 344: 1750-1757.

Bianco P, Riminucci M, Gronthos S, Robey PG. Bone marrow stromal stem cells: nature, biology and potential applications. Stem Cells. 2001; 19: 180-192.

Caplan AI. Mesenchymal stem cells. J Orthop Res. 1991; 9: 641-650.

Caplan AI. Adult mesenchymal stem cells for tissue engineering versus regenerative medicine. $J$ Cell Physiol. 2007; 213: 341-347.

Cardoso TC, Ferrari HF, Garcia AF, Novais JB, SilvaFrade C, Ferrarezi MC, et al. Isolation and characterization of Wharton's jelly-derived multipotent mesenchymal stromal cells obtained from bovine umbilical cord and maintained in a defined serum-free three-dimensional system. BMC Biotech. 2012; 12: 1-11.

Cohnheim, J. Ueber entzündung und eiterung. Path Anat Physiol Klin Med. 1867; 40:1.

De Ugarte DA, Alfonso Z, Zuk PA, Elbarbary A, Zhu M, Ashjian P, et al. Differential expression of stem cell mobilization-associated molecules on multi- 
lineage cells from adipose tissue and bone marrow. Immunol Lett. 2003; 89: 267-270.

Dezawa $\mathrm{M}$, Ishikawa $\mathrm{H}$, Itokazu $\mathrm{Y}$, Yoshihara $\mathrm{T}$, Hoshino $\mathrm{M}$, Takeda $\mathrm{S}$, et al. Bone marrow stromal cells generate muscle cells and repair muscle degeneration. Sci. 2005; 309: 314-317.

Dicker A, Le Blanc K, A $^{\circ}$ stro“m G, Van Harmelen V, Go"therstro "m C, Blomqvist L. Functional studies of mesenchymal stem cells derived from adult human adipose tissue. Exp Cell Res. 2005; 308: 283-290.

Efimenko A, Starostina E, Kalinina N, Stolzing A. Angiogenic properties of aged adipose derived mesenchymal stem cells after hypoxic conditioning. $J$ Transl Med. 2011; 9: 1-13.

Fathi E, Farhzadi R. Survey on impact of trace elements $(\mathrm{Cu}, \mathrm{Se}$ AND $\mathrm{Zn})$ on veterinary and human mesenchymal stem cells. Rom J Biochem. 2015; 52:67-77.

Fathi E, Nassiri SM, Atyabi N, Ahmadi SH, Imani M, Farahzadi R, et al. Induction of angiogenesis via topical delivery of basic-fibroblast growth factor from polyvinyl alcohol dextran blend hydrogel in an ovine model of acute myocardial infarction. J Tissue Engin Regen Med. 2013; 9: 697-707.

Fernández-García M, Yañez RM, Sánchez-Domínguez R, Hernando-Rodriguez M, Peces-Barba M, Herrera $\mathrm{G}$, et al.

Mesenchymal stromal cells enhance the engraftment of hematopoietic stem cells in an autologous mouse transplantation model. Stem Cell Res Ther. 2015; 6: 165-177.

Friedenstein AJ, Chailakhyan RK, Latsinik NV, Panasyuk AF, Keiliss-Borok IV. Stromal cells responsible for transferring the microenvironment of the hemopoietic tissues: cloning in vitro and retransplantation in vivi. Transplant. 1974; 17:331440.

Gimble JM. Adipose tissue-derived therapeutics. Expert Opin Biol Ther. 2003; 3: 705-713.

Gimble JM, Katz AJ, Bunnell BA. Adipose-derived stem cells for regenerative medicine. Circ Res. 2007; 100: 1249-1260.

Hall MN, Rosenkrantz WS, Hong JH, Griffin CE, Mendelsohn CM. Evaluation of the potential use of adipose-derived mesenchymal stromal cells in the treatment of canine atopic dermatitis: A pilot study.Vet Ther. 2010; 11: 1-14.

Hass R, Kasper C, Böhm S, Jacobs R. Different populations and sources of human mesenchymal stem cells (MSC): A comparison of adult and neonatal tissue-derived MSC. Cell Commun Signal. 2011; 9: 114.

Herrera MB, Bussolati B, Bruno S, Fonsato V, Romanazzi GM, Camussi G. Mesenchymal stem cells contribute to the renal repair of acute tubular epithelial injury. Int J Mol Med. 2004; 14: 1035-1041.

Huangm SP, Huang CH, Shyu JF, Lee HS, Chen SG, Yi-Hsin Chan J, et al. Promotion of wound healing using adipose-derived stem cells in radiation ulcer of a rat model. J Biomed Sci. 2013; 20: 2-10.

Jeon ES, Moon HJ, Lee MJ, Song HY, Kim YM, Bae $\mathrm{YC}$, et al. Sphingosylphosphorylcholine induces differentiation of human mesenchymal stem cells into smooth-muscle-like cells through a TGF-betadependent mechanism. J Cell Sci. 2006; 119: 49945005.

Jin XB, Sun YS, Zhang K, Wang J, Ju XD, Lou SQ. Neocartilage formation from predifferentiated human adipose derived stem cells in vivo. Acta Pharmacol Sin. 2007; 28: 663-671.

Jing $\mathrm{W}, \mathrm{Wu}$ L, Lin Y, Liu L, Tang W, Tian W. Odontogenic differentiation of adipose-derived stem cells for tooth regeneration: necessity, possibility, and strategy. Med Hypotheses. 2008; 70: 540-542.

Jurgens WJFM, Oedayrajsingh-Varma MJ, Helder MN. Effect of tissue-harvesting site on yield of stem cells derived from adipose tissue: implications for cellbased therapies. Cell Tissue Res. 2008; 332: 415-426.

Kern S, Eichler H, Stoeve J, Kluter H, Bieback K. Comparative analysis of mesenchymal stem cells from bone marrow, umbilical cord blood, or adipose tissue. Stem Cells. 2006; 24: 1294-1301.

Kim JH, Park SG, Kim WK, Song SU, Sung JH. Functional Regulation of Adipose-Derived Stem Cells by PDGF-D. Stem Cells. 2015; 33: 542-556.

Ko KS, Lee IW, Joo WI, Lee KJ, Park HK, Rha HK. Differentiation of human adult adipose derived stem cell in vitro and immunohistochemical study of adipose derived stem cell after intracerebral transplantation in rats. $J$ Korean Neurosurg Soc. 2007; 42: 118-124.

Kuo CK, Tuan RS. Mechanoactive tenogenic differentiation of human mesenchymal stem cells. Tissue Engin Part A. 2008; 14: 1615-27.

Lu LL, Liu YJ, Yang SG, Zhao QJ, Wang X, Gong W. Isolation and characterization of human umbilical cord mesenchymal stem cells with hematopoiesissupportive function and other potentials. Haematol. 2006; 91: 1017-1026.

Mallette FA, Gaumont-Leclerc MF, Huot G, Ferbeyre G. Myc downregulation as a mechanism to activate the $\mathrm{Rb}$ pathway in STAT5Ainduced senescence. $J$ Biol Chem. 2007; 282: 34938-34944.

Meza-Zepeda LA, Noer A, Dahl JA, Micci F, Myklebost O, Collas P. Highresolution analysis of genetic stability of human adipose tissue stem cells cultured to senescence. J Cell Mol Med. 2008; 12: 553-563.

Mitchell JB, McIntosh K, Zvonic S. Immunophenotype of human adipose-derived cells: temporal changes in stromal-associated and stem cell-associated markers. Stem Cells. 2006; 24: 376-385.

Nakanishi CH, Nagaya N, Ohnishi SH, Yamahara K, Takabatake S, Konno $\mathrm{T}$, et al. Gene and protein expression analysis of mesenchymal stem cells 
derived from rat adipose tissue and bone marrow. Circ J. 2011; 75: 2260-2268.

Noer A, Sørensen AL, Boquest AC, Collas PH. Stable $\mathrm{CpG}$ hypomethylation of adipogenic promoters in freshly isolated, cultured, and differentiated mesenchymal stem cells from adipose tissue. Mol Biol Cell. 2006; 17: 3543-3556.

Noer A, Boquest AC, Collas P. Dynamics of adipogenic promoter DNA methylation during clonal culture of human adipose stem cells to senescence. BMC Cell Biol. 2007; 8: 18.

Oedayrajsingh Varma MJ, Breuls RGM, Schouten TE, Jurgens WJFM, Bontkes HJ, Schuurhuis GJ, et al. Phenotypical and functional characterization of freshly isolated adipose tissue-derived stem cells. Stem Cells Dev. 2007; 16: 91-104.

Oswald J, Boxberger S, Jørgensen B, Feldmann S, Ehninger G, Bornha“user M, et al. Mesenchymal stem cells can be differentiated into endothelial cells in vitro. Stem Cells. 2004; 22: 377-384.

Park A, Hogan MV, Kesturu GS, James R, Balian G, Chhabra AB. Adipose-derived mesenchymal stem cells treated with growth differentiation factor-5 express tendon-specific markers. J Tissue Engin. 2010; 16: 2941-2951.

Pennington EC, Gray FL, Ahmed A, Zurakowski D, Fauza DO. Targeted quantitative amniotic cell profiling: a potential diagnostic tool in the prenatal management of neural tube defects. J Pediatr Surg. 2013; 48:1205-1210.

Poznanski WJ, Waheed I, Van R. Human fat cell precursors. Morphologic and metabolic differentiation in culture. Lab Invest. 1973; 29: 570-576.

Ren Y, Wu H, Zhou X, Wen J, Jin M, Cang M, et al. Isolation, expansion, and differentiation of goat adipose-derived stem cells. ResVet Sci. 2012; 93: 404411.

Shim WS, Jiang S, Wong P, Tan J, Chua YL, Tan YS, et al. Ex vivo differentiation of human adult bone marrow stem cells into cardiomyocyte like cells. Biochem Biophys Res Commun. 2004; 324:481-488.

Strioga M, Viswanathan S, Darinskas A, Slaby O, Michalek J. Same or not the same? Comparison of adipose tissue-derived versus bone marrow-derived mesenchymal stem and stromal cells. Stem Cells Dev. 2012; 21: 2724-52.

Torres FC, Rodrigues CJ, Stocchero IN, Ferreira MC. Stem cells from the fat tissue of rabbits: An easytofind experimental source. Aesthet Surg. 2007; 31: 574-578.

Tsai CC, Chen YJ, Yew TL, Chen LL, Wang JY, Chiu $\mathrm{CH}$, et al. Hypoxia inhibits senescence and maintains mesenchymal stem cell properties through downregulation of E2A-p21 by HIF-TWIST. Blood. 2011; 117: 459-469.

Van Harmelen V, Rohrig K, Hauner H. Comparison of proliferation and differentiation capacity of human adipocyte precursor cells from the omental and subcutaneous adipose tissue depot of obese subjects. Metabolism. 2004; 53: 632-637.

Valenti MT, Mori A, Malerba G, Carbonare LD. Mesenchymal stem cells: A new diagnostic tool? World J Stem Cells. 2015; 7: 789-792.

Vidal MA, Kilroy GE, Lopez MJ, Johnson JR, Moore RM, Gimble JM. Characterization of equine adipose tissue-derived stromal cells: Adipogenic and osteogenic capacity and comparison with bone marrow derived mesenchymal stromal cells. Vet Surg. 2007; 36: 613-622.

Vieira NM, Brandalise V, Zucconi E, Secco M, Strauss BE, Zat M. Isolation, Characterization, and Differentiation Potential of Canine Adipose-Derived Stem Cells. Cell Transplant. 2010; 19: 279-289.

Wagner W, Ho AD, Zenke M. Different facets of aging in human mesenchymal stem cells. Tissue Engin Part B. 2010; 16: 445-453.

Wei G, Schubiger G, Harder F, Muller AM. Stem cells plasticity in mammals and transdetermination in Drosophila: common theme? Stem Cells. 2000; 18: 409-414.

Williams KJ, Picou AA, Kish SL, Giraldo AM, Godke RA, Bondioli K.R. Isolation and characterization of porcine adipose tissue-derived adult stem cells. Cells Tissues Organs. 2008; 188: 251-258.

Yamamoto N, Akamatsu H, Hasegawa S, Yamada T, Nakata S, Ohkuma M, et al. Isolation of multipotent stem cells from mouse adipose tissue. J Dermatol Sci. 2007; 48: 43-52.

Zaminy A, Ragerdi Kashani I, Barbarestani M, Hedayatpour A, Mahmoudi R, Farzaneh Nejad A. Osteogenic differentiation of rat mesenchymal stem cells from adipose tissue in comparison with bone marrow mesenchymal stem cells: melatonin as a differentiation factor. Iran Biomed J. 2008; 12: 133 141.

Zhu Y, Liu T, Song K, Fan X, Ma X Cui Z. Adiposederived stem cell: a better stem cell than BMSC. Cell Biochem Funct. 2008; 26: 664-675.

Zhu M, Kohan E, Bradley J, Hedrick M, Benhaim P, Zuk P. The effect of age on osteogenic, adipogenic andproliferative potential of female adipose-derived stem cells. J Tissue Engin Regen Med. 2009; 3: 290301.

Received: 06-Jul-2015 Accepted: 28-Sept-2015 


\section{BRAZILIAN ARCHIVES OF BIOLOGY AND TECHNOLOGY}

AN INTERNATIONAL JOURNAL

\section{Erratum}

In Article "Isolation, Culturing, Characterization and Aging of Adipose Tissue-derived Mesenchymal Stem Cells: A Brief Overview", with the number of DOI:http://dx.doi.org/10.1590/1678-4324-2016150383, published in journal Brazilian Archives of Biology and Technology, vol. 59, the 01 page.

that read:

"I Young Researchers And Elite Club, Tabriz Branch, Islamic Azad University, Tabriz, Iran, Tabriz, Iran (the Islamic Republic of); ' Department of Clinical Sciences, Faculty of Veterinary Medicine, University of Tabriz, Tabriz, Iran. Tabriz , Iran (the Islamic Republic of)"

Read:

"IDepartment of Clinical Sciences, Faculty of Veterinary Medicine, University of Tabriz, Tabriz, Iran; ${ }^{2}$ Young Researchers And Elite Club, Tabriz Branch, Islamic Azad University, Tabriz, Iran." 